\title{
Plaxis 在深基坑开挖过程中的数值模拟和应用
}

\section{Numerical Simulation and Application of Plaxis in Deep Foundation Pit Excavation \\ 王健 黄晓冀 陈晨 杨明}

Jian Wang Xiaoji Huang Chen Chen Ming Yang

中国矿业大学(北京)力学与建筑工程学院 中国·北京 100083

School of Mechanics and Civil Engineering, China University of Mining and Technology-Beijing, Beijing, 100083, China

基金项目:中国矿业大学(北京)2016 级大 学生创新实践项目, 北京市大学生科学研 究与创业行动计划项目 (C201806141)。
【摘要】岩土工程有限元分析软件 PLAXIS 2D 目前已经被广泛地应用于深基坑开挖工程 的数值模拟中。论文使用 PLAXIS 2D 对地下连续墙支护下的基坑开挖的施工全过程进行 了数值模拟,得出了基坑开挖过程对支护结构及其周边土体的影响,为今后同类问题的研 究积累了经验。

【Abstract】PLAXIS 2D, a geotechnical finite element analysis software, has been widely used in the numerical simulation of deep foundation pit excavation. In this paper, PLAXIS 2D is used to conduct numerical simulation of the whole process of foundation pit excavation under underground continuous wall support, and the influence of foundation pit excavation process on the supporting structure and surrounding soil is obtained, thus accumulating experience for future research on similar problems.

【关键词】深基坑; 地下连续墙; 有限元分析; 数值模拟;PLAXIS 2D

【Keywords \deep foundation pit; underground diaphragm wall; finite element analysis; numerical simulation PLAXIS 2D

【DOI】10.36012/etr.v2i4.1721

\section{1 引言}

地铁车站的基坑尺寸目前越来越向着深、宽、大的方向发 展, 开挖过程中一旦破坏可能会造成巨大的经济损失和人员伤 亡事故。因此,深基坑的开挖和支护一直是工程施工的重点和 难点。论文使用 PLAXIS 2D 对北京地铁 14 号线永丰南站标 准段基坑开挖过程进行了数值模拟和研究, 得出了基坑开挖 的施工过程对支护结构及其周边土体的影响, 达到了利用数 值分析结果对施工过程给予比较准确的指导 ${ }^{[1]}$ 。

\section{2 工程概况}

\section{1 工程背景}

论文以北京地铁 14 号线永丰南站标准段为工程背景, 位 于永丰南环路与永丰路交叉路口以南,沿永丰路南北向布置。 永丰南站为地下两层岛式车站, 双柱三跨混凝土结构, 施工方 法采用明挖法。

\section{2 地层条件}

该工程的主要地层为杂填土层、粉质黏土层、粉土层、粉 细砂层、中粗砂层等土层。地下水位较高, 潜水(二)水位标高 $31.32 \sim 29.67 \mathrm{~m}$, 层间潜水 (三)水位标高 18.66 17.82m, 层间潜
水(四)水位标高 $5.5 \sim 6 \mathrm{~m}$ 。

各层土地层分布自上而下依次如下:

杂填土 1 层: 内摩擦角为 $8^{\circ}$, 黏聚力为 $10 \mathrm{kPa}$, 压缩模量 为 $10 \mathrm{Mpa}$ 。

粉质黏土层 4 层: 内摩擦角为 $20^{\circ}$, 黏聚力为 $28 \mathrm{kPa}$, 压缩 模量平均分布在 $6.78 \mathrm{MPa}$ 。

粉细砂 1 层: 内摩擦角为 $30^{\circ}$, 黏聚力为 0 , 压缩模量为 $32.5 \mathrm{Mpa}$ 。

粉质黏土 1 层: 内摩擦角为 $15^{\circ}$, 黏聚力为 $30 \mathrm{kPa}$, 压缩模 量为 $16.61 \mathrm{Mpa}$ 。

黏土 1 层: 内摩擦角为 $20^{\circ}$, 黏聚力为 $25 \mathrm{kPa}$, 压缩模量为 $15.15 \mathrm{Mpa}$

\section{3 数值模拟过程}

\section{1 建模原则}

(1)采用二维数值模型, 按实际施工过程分步模拟, 考虑深 基坑开挖过程中，车站主体结构的受力及其对周边土体的影 响过程。(2)土层厚度、土层力学参数等按照勘察报告提交的参 数进行选取, 在不同的纵断面位置, 按照建模位置对应的参数 选取，土层厚度变化的按照临近的钻孔揭露的该土层位置平 


\section{实验与研究 Experiments and Research}

均值选取。(3)本次数值计算中, 土体本构采用摩尔库伦模型, 土体为不排水状态。(4)建模假定工程开挖实际揭露地层状况 与勘察揭露的勘察报告论述的地层状况及强度参数一致, 不 考虑局部地层状况与勘察报告的差异性 ${ }^{[2]}$ 。

\section{2 模型尺寸选取及边界条件}

为了使模型尺寸基本可以消除边界效应对计算结果的影 响, 所有边界均为位移边界条件, 其中模型上表面为自由边 界, 下表面方向位移固定, 左右边界为 $x$ 方向位移固定。

\section{3 定义结构和土体及其相互作用单元}

此模块中使用板单元模拟地下连续墙, 材料种类设置为 弹塑性, 轴向刚度 $\mathrm{EA}=1.080 \times 10^{7} \mathrm{KN} / \mathrm{m}$, 抗弯刚度 $\mathrm{EI}=3.24 \times$ $10^{5} \mathrm{~m}^{2} / \mathrm{m}$, 重度 $\omega=9 \mathrm{KN} / \mathrm{m} / \mathrm{m}$, 泊松比 $V=0.2$; 使用针杆单元模拟 内支撑, 材料种类设置为弹性, 轴向刚度为 $\mathrm{EA}=6.119 \times 10^{\circ} \mathrm{KN}$, 水平间距 $L_{s}=3 \mathrm{~m}$ 。线单元划分开挖面, 在墙两侧与土体之间添 加界面单元。使用点对点的针杆单元来模拟内支撑, 并在施工 阶段施加预应力。

使用界面单元 (图 1) 来模拟地下连续墙与土之间的 相互作用。Plaxis 中界面的单元的模拟是通过强度折减因子 $R$ 来实现的, 这里 $R$ 取 0.8 。

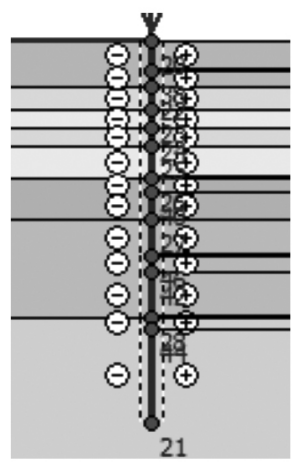

图 1 墙两侧添加界面单元

\section{4 网格生成和计算}

该工程生成网格粗细程度为中。单击“一初始条件”开始 设置初始条件, 计算如图 2 所示, 计算结果和手算结果相当。 “一计算”进入计算程序中, 输入前一步工序后, 点击下一步, 添加下道工序。在模型中建立开挖及加撑阶段时,计算类型选 择为<塑性分析>。加载类型选择为分布施工, 在弹出的模型 中选择具体施工内容。计算中采用摩尔-库仑弹塑性模型, 基 坑围护结构与土体之间的接触面运用接触单元。通过计算得 出不同开挖阶段的地表沉降、基底隆起和墙后土体水平位移, 为工程设计与施工提供参考。最后的施工工序为固结阶段, 为 观察施工完一段时间后土体的的固结沉降情况,在完成所有工 序后加入固结分析步序。加载类型选择为最小的孔压, 输入值为

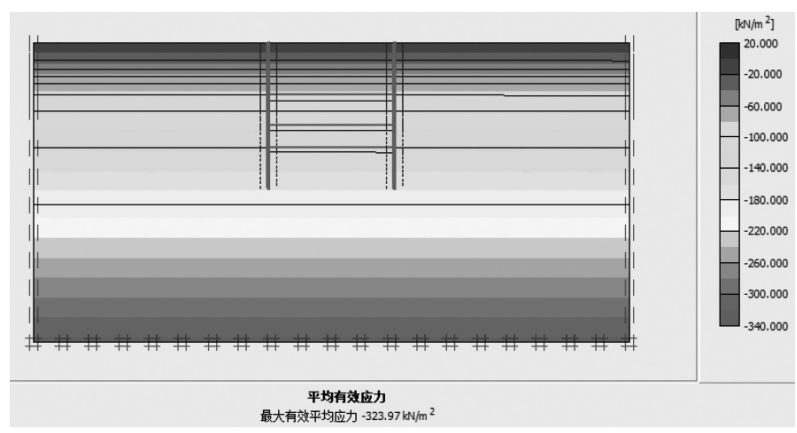

图 2 查看土的初始应力

土体的压缩系数 0.21 。

\section{4 数值分析结果和输出处理}

计算成功后, 进入输出程序。输出窗口不仅可以看到土的 位移和应力, 还可查看各结构的内力。在变形菜单中, 选择查 看各位移图、增量图; 在应力菜单中, 选择查看总应力、有效应 力、水压力分布图。本案例的总应力图如图 3 所示。

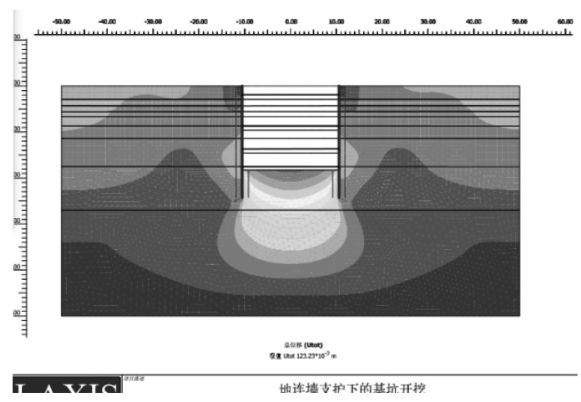

图 3 基坑开挖完成的总应力图

对于结构的内力可以通过双击结构单元, 弹出显示该结 构内力的窗口, 点击内力菜单中选择查看结构的轴力、剪力 和如图 4 所示的弯矩图。基坑开挖完成的总位移图如图 5 所示。

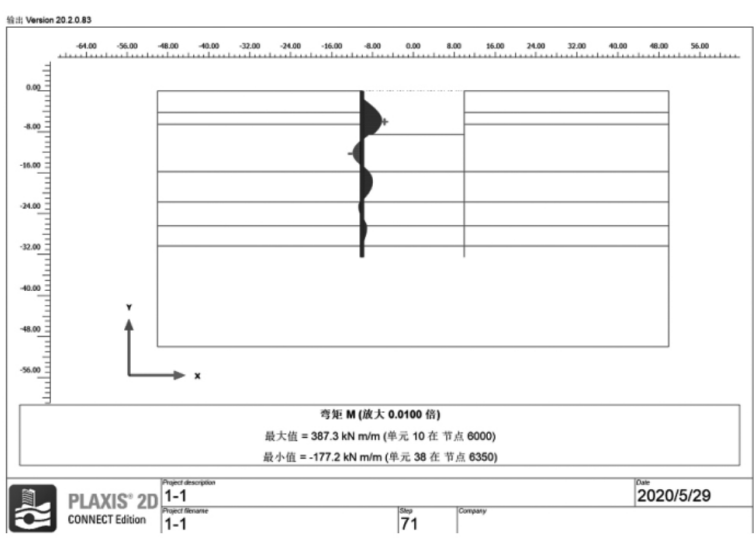

图 4 基坑开挖过程中左侧连续墙体的弯矩图

\section{5 结语}

在有限元模型中, 模拟基坑的整个开挖、支护过程, 就是 


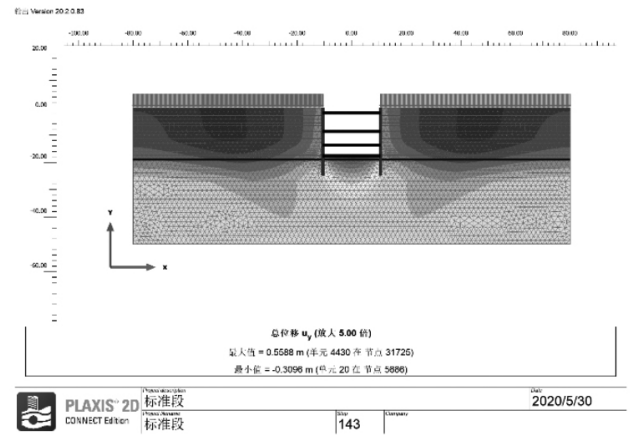

图 5 基坑开挖完成的总位移图

将每一个施工阶段对应的工况反映到模型的变化中, 可得到 其中的一个施工步的分析结果，以及连续施工情况下整个模 型的系统响应 ${ }^{[4]}$ 。对应到 PLAXIS 软件中, 主要是对每一个施 工阶段进行开挖土层的冻结、相应支护结构的激活(包括接触 关系）、荷载的激活与冻结、土层水力条件的修改等, 如果考虑 坑底土层加固等工程措施, 还需要修改对应土层的材料属性。 总之, 基坑开挖分析是一个施工过程的模拟, 必须注重施工顺 序对整体工程系统的影响。在添加固结分析阶段, 选择加载方 式为最小的孔压, 即模拟土体中孔隙水压力消散至某一固定 值时的土体固结情况。将最小孔压值设定为土体的压缩系数,
即模拟当土体完全固结时的固结情况。

基坑支护结构除了要达到快速建模之外, 还要注重简化 结构的主要受力体系, 采用恰当的结构单元, 以达到高效、准 确的求解分析。同时,对地下水控制的合理分析、孔隙水压力 的准确评估, 也关系到土层力学行为及结构受力情况的变化。 为此,本文对挡土结构、结构与土层相互作用、内支撑系统及 针杆系统的模拟做了系统性介绍。此外，在施工过程模拟当 中, 要注意实际施工过程与模型分析工况的对应和吻合, 以利 用数值分析结果对施工过程给予比较准确的指导 ${ }^{[5]}$ 。

\section{参考文献}

[1]左殿军,史林,李铭铭,等.深基坑开挖对邻近地铁隧道影响数值 计算分析[J].岩土工程学报,2014,36(S2):391-395.

[2]刘小丽,马悦,郭冠群,等.PLAXIS2D 模拟计算基坑开挖工程的 适用性分析 [J].中国海洋大学学报(自然科学版),2012,42(4):19-25.

[3]付先进,林作忠. 基于 plaxis 的超深基坑开挖弹塑性有限元数 值计算与分析[J].中国水运(下半月),2010,10(4):190-192.

[4]姚远. 基于 PLAXIS 的基坑开挖模拟研究 [J].低温建筑技术, 2019,41(6)93-95.

[5]曹文峰.连续墙支护深基坑开挖过程有限元分析 [J].黑龙江工 程学院学报,2019,33(6):24-27.
（上接第 166 页）

$$
P_{i}=\frac{\exp \left(\sum_{k=1}^{K} \theta_{h} X_{i k}\right)}{\sum_{j} \exp \left(\sum_{k=1}^{K} \theta_{k} X_{i k}\right)}
$$

针对论文考虑双流机场陆侧 5 种地面交通方式用式 (16) 可得各效用值, 具体计算过程和结果如下:

$$
\mathrm{V}_{\text {地铁 }}=0.119 \times 4+0.413 \times 4+0.061 \times 3+0.381 \times 2+0.089 \times 1=0.306
$$

同理可得 $V_{\text {机场大巴 }}=2.355, V_{\text {出租车 }}=2.876, V_{\text {网约车 }}=3.061, V_{\text {私家车 }}=$ 3.342 。根据以上求得的 5 种交通方式的效用值, 对双流机场 陆侧交通方式 5 种主要交通方式进行分析，通过如下计算可 以得到地铁 10 号线的分担率预测值:

$$
\begin{aligned}
P_{\text {地铁 }}= & \exp \left(V_{\text {地铁 }}\right) /\left[\exp \left(V_{\text {地铁 }}\right)+\exp \left(V_{\text {机场大巴 }}\right)+\exp \left(V_{\text {出租车 }}\right)\right. \\
& \left.+\exp \left(V_{\text {网约车 }}\right)+\exp \left(V_{\text {私家车 }}\right)\right]=21.08 \%
\end{aligned}
$$

同理计算得到其他 4 种交通方式的分担率，得到地铁的 分担率为 $21.08 \%$, 机场大巴为 $10.68 \%$, 出租车为 17.96 , 网约 车为 21.63 , 私家车为 28.65 。

地铁和机场大巴两者共同分担的旅客共占约 $32 \%$, 出租 车和网约车两者共同分担的旅客占约 $40 \%$ 。结合此数据预测 2018 年和当机场吞吐量达到 6000 万人次时，当地铁对双流
机场陆侧一直保持在目前预测的分担率的情况下,2018 年成 都地铁 10 号线对双流机场陆侧日均分担量为 486613 人次; 当机场吞吐量达到 6000 万人次时, 成都地铁 10 号线对双流 机场陆侧日均分担量为 57952 人次。

\section{5 结语}

论文在对成都双流机场特定年的吞吐量进行预测的基础 上，使用 Logit 模型对成都地铁 10 号线一期对双流机场陆侧 交通分担率进行预测，模型中采用层次分析法来确定模型中 特性指标的参数;下一步可以对各个权重进行进一步的更新, 以提高分担率预测精准度; 得到预测分担率后, 再对地铁的具 体分担量进行预测。

\section{参考文献}

[1]Phang S Y.Strategic development of airport and rail infrastructure: the case of Singapore[J]. Transport Policy, 2003,10(1):27-33.

[2]Janić M.Light Rail Rapid Transit systems for more sustainable ground accessibility of airports[J]. Transportation Planning and Technology,2011,34(6):569-592.

[3]姚晏斌. 大容量机场轨道交通对陆侧交通的分流预测 [D]. 天 津:中国民航大学,2006. 